\title{
DNA methylation in embryonic stem cells
}

\author{
Gulsah Altun $^{1,2}$, Jeanne F. Loring ${ }^{2}$, and Louise C. Laurent ${ }^{1,2,}$ \\ ${ }^{1}$ University of California, San Diego. Department of Reproductive Medicine. San Diego, CA \\ ${ }^{2}$ The Scripps Research Institute. Center for Regenerative Medicine and Department of Chemical \\ Physiology. La Jolla, CA
}

\begin{abstract}
Embryonic stem cells (ESCs) are pluripotent, self-renewing cells. These cells can be used in applications such as cell therapy, drug development, disease modeling, and the study of cellular differentiation. Investigating the interplay of epigenetics, genetics, and gene expression in control of pluripotence and differentiation could give important insights on how these cells function. One of the best known epigenetic factors is DNA methylation, which is a major mechanism for regulation of gene expression. This phenomenon is most clearly seen in the case of imprinted genes, where DNA methylation of promoter regions leads to strong repression of gene expression.

Differential DNA methylation of pluripotence-associated genes such as Nanog and Oct4/Pou5f1 has been observed between pluripotent and differentiated cells. It is clear that tight regulation of DNA methylation is necessary for normal development. As more associations between aberrant DNA methylation and disease are reported, there has been increasing demand for high-throughput approaches for DNA methylation analysis. In this article, we highlight these methods and discuss recent DNA methylation studies on ESCs.
\end{abstract}

\section{Keywords}

DNA methylation; embryonic stem cells; epigenetics; microarray; next-generation sequencing

\section{Introduction}

Because of their abilities to self-renew and differentiate into a wide variety of cell types, embryonic stem cells (ESCs) and other pluripotent stem cells hold tremendous promise for drug development and cell replacement therapy. However, these applications call for homogeneous, stable cell populations that possess specific characteristics while lacking undesirable properties. For example, for treatment of diabetes, we would want cells that stably produce insulin in a glucose-responsive manner, and do not form tumors. In order to produce the right cells for these applications, it will be important to understand the mechanisms that control critical cellular properties, such as differentiation capacity, differentiation state, and tumorigenicity.

There is no question that genetic factors can strongly influence cellular and organismal phenotype. However, the fact that all of the cells in a multicellular organism arise from a single original cell indicates that tremendous phenotypic variability can occur among cells that share a common genome. On the organismal level, it has been shown that monozygotic twins can differ in disease susceptibility and many anthropomorphic features [Fraga et al.,

\footnotetext{
*Corresponding author llaurent@ucsd.edu phone: (858) 7847135 fax: (858) 7847211 Address: University of California, San Diego, Department of Reproductive Medicine, 200 West Arbor Drive, San Diego, CA, 92103.
} 
2005]. These phenotypic differences in the context of a common genome are attributed to epigenetic factors. Disruption in epigenetic regulation, such as aberrant DNA methylation, can lead to malformation or disease [Costello et al., 2000; Robertson, 2005].

Epigenetics is a term coined more than 65 years ago [Waddington, 1942] to convey the idea that differentiation from the fertilized egg to adult tissues occurs through progressive nongenetic changes. In recent years, the term has taken on a more molecular connotation; $\mathrm{Wu}$ and Morris [Wu and Morris, 2001] define epigenetics as "the study of changes in gene function that are mitotically and/or meiotically heritable and that do not entail a change in DNA sequence.".

Using a rather broad interpretation of the term, epigenetic processes include modulation of chromatin structure, miRNA expression, and DNA methylation. Chromatin consists of nuclear genomic DNA packaged by histones and other associated proteins. Transcription, DNA replication, repair and recombination are dynamically modulated by changes in chromatin structure. Chromatin structure, in turn, can be influenced either by the presence or absence of specific proteins, such as transcription factors, or by chemical modifications of constitutively bound proteins, such as histones [Schones and Zhao, 2008; Strahl and Allis, 2000]. MicroRNAs (miRNAs) are small (18-25 nucleotides) RNA molecules that posttranscriptionally regulate gene expression. miRNAs can act by destabilizing target mRNAs or repress translation, with the latter mechanism more prevalent in metazoans [Bartel, 2009].

DNA methylation is an enzyme-mediated chemical modification of DNA involving addition of a methyl group symmetrically on the cytosines of $\mathrm{CpG}$ dinucleotides. This reaction is catalyzed by a group of enzymes, the DNA methyltransferases (DNMTs). In humans and other mammals, DNA methylation usually happens on cytosines that precede a guanosine in the DNA sequence. This is called a "CpG" dinucleotide and nearly $70 \%-80 \%$ of all $\mathrm{CpG}$ dinucleotides are methylated [Bird, 2002]. In the genome, dense clusters of CpGs are observed in some areas. These clusters, which are usually 300-3,000 base pairs in length, are called "CpG islands" [Bird, 1986; Gardiner-Garden and Frommer, 1987]. CpG islands are associated with approximately $70 \%$ of human promoters [Davuluri et al., 2001; Saxonov et al., 2006]. For genes with $\mathrm{CpG}$ islandcontaining promoter regions, it has been observed that methylation of the $\mathrm{CpG}$ island is inversely correlated with gene expression. For this reason, $\mathrm{CpG}$ islands have been the main focus for methylation analysis.

It is known that DNA methylation can regulate gene expression. In imprinted genes, methylation of promoter regions results in strong repression of gene expression [ $\mathrm{Li}$ et al., 1993]. In cancer cells, where DNA methylation was the first epigenetic alteration to be observed, hypermethylation of $\mathrm{CpG}$ islands near tumor suppressor genes has been shown to switch off these genes [Herman et al., 1994; Jones and Laird, 1999].

The study of epigenetic mechanisms in the establishment and maintenance of the pluripotent state, as well as in the differentiation process, is an area of intense investigation in ESC biology. In addition, since ESCs and cancer cells share certain phenotypic characteristics, such as the ability to be propagated in long-term culture, there has been interest in establishing whether they share certain epigenetic characteristics.

The roles of all three epigenetic mechanisms in ESCs were reviewed in 2008 by Bibikova et al. [Bibikova et al., 2008]. However, there has been rapid progress in this field, particularly in the area of DNA methylation. In this review, we will give an overview of the existing methods for studying DNA methylation, and review the key DNA methylation studies specific to ESCs, with an emphasis on reports published over the past year. 


\section{Methods for detecting DNA methylation}

Methods for DNA methylation are mainly based on the following techniques:

1. Affinity purification of methylated DNA.

2. Digestion with methylation-sensitive restriction enzymes

3. Bisulfite conversion

\subsection{Affinity purification}

In this method, methylated DNA is purified using either a methyl-CpG binding domain (MBD) or, more commonly, an antibody specific for methylated cytosine [Cross et al., 1994; Weber et al., 2005]. Genomic DNA fragments containing methylated cytosines are immunoprecipitated and analyzed by hybridization to microarrays (Methylated DNA Immunoprecipitation-chip, or MeDIP-chip) or next-generation sequencing (MeDIP-seq).

The MeDIP-chip approach has been used to obtain whole-genome DNA methylation data from Arabidopsis thaliana [Zhang et al., 2006]. This approach can provide wholegenome coverage, but the resolution is limited by the resolution of the microarrays used. Moreover, for typical high-density microarray platforms ( 1-2 million assays per array), wholegenome coverage at a reasonable resolution ( $\sim 100$ bp probe interval) requires $10-20$ arrays, which can be quite costly.

In MeDIP-seq, the sequence of the affinity-purified DNA fragments is obtained and aligned to a reference genome. Even though MeDIP-seq [Down et al., 2008] offers higher resolution compared to MeDIP-chip, single nucleotide resolution is still not provided by this approach, because it is based on affinity purification of segments of methylated DNA. If a fragment contains several cytosine nucleotides, methylation of any one of them will result in enrichment of that fragment in the affinity purification step.

\subsection{Methylation-sensitive restriction enzymes}

Methylation-sensitive restriction enzymes cleave specific DNA sequences in a methylationsensitive manner [Bird and Southern, 1978]. Some methylation-sensitive restriction enzymes, such as HpaII (which recognizes the sequence 5'-...CCGG...-3'), cleave only unmethylated DNA, which others, such as MspI (which recognizes the same 5'... CCGG...-3' sequence), cleave only methylated DNA.

These enzymes are the basis of restriction landmark genomic scanning (RLGS), which has been used to assess global DNA methylation [Hatada et al., 1991]. In RLGS, genomic DNA is cleaved using a methylation-sensitive restriction enzyme (such as NotI, which does not cleave at recognition sites that are methylated), end-labeled, and run on a 2-dimensional gel. Only unmethylated recognition sites are represented in the RLGS map. If a spot is present in the profile for one cell type (e.g. normal cells) and absent in another (e.g. tumor cells), this indicates that a recognition site is unmethylated in the normal cells and methylated in the tumor cells. RLGS reveals large numbers of restriction landmarks in a single experiment, but is limited by the difficulty in correlating individual spots to specific sequences.

Another strategy based on methylation-sensitive restriction enzymes is Methyl-Sensitive Cut Counting (MSCC), which is a next-generation sequencing approach [Ball et al., 2009]. For MSCC, genomic DNA is cleaved using HpaII (or another restriction enzyme that cleaves only unmethylated recognition sites), and an adaptor containing MmeI (or another type-II restriction enzyme, which cleaves several base-pairs away from its recognition sequence) is ligated. The DNA is digested with MmeI and the fragments are ligated, to a second adaptor 
to allow amplification of sequences adjacent to unmethylated HpaII recognition sequences. The amplified sequences are subjected to next-generation sequencing, revealing the methylation status of all HpaII recognition sites in the genome [Ball et al., 2009]. MSCC provides single-nucleotide resolution, but is limited to interrogating the methylation status of sequences recognized by HpaII (or another methylation-sensitive restriction enzyme).

\subsection{Bisulfite conversion}

Bisulfite conversion is currently one of the most widely used techniques for DNA methylation analysis. First described by Frommer et al. [Frommer et al., 1992], this technique involves the treatment of DNA with sodium bisulfite, which deaminates unmethylated cytosines (C), converting them into uracils (U). Methylated cytosines are not changed by bisulfite treatment. By comparing the sequences of unconverted and converted DNA, it is possible to identify unmethylated sites (where C's in the unconverted DNA are read as T's (thymine) in the converted DNA) and methylated sites (which are read as C's in both the unconverted and converted DNA). This technique depends on highly efficient bisulfite conversion (current methods result in unmethylated $\mathrm{C}$ to $\mathrm{U}$ conversion levels of greater than 99\%), and can provide single-nucleotide resolution data.

\subsubsection{Methylation-specific PCR (MSP)}

In Methylation-specific PCR (MSP), the bisulfite-converted DNA is subjected to quantitative PCR with primers specific for methylated versus unmethylated DNA [Herman et al., 1996]. This can give an accurate measurement of the ratio of unmethylated C's to methylated C's. This method can provide single-nucleotide resolution, but is restricted to selected areas of the genome. It can be very useful for interrogating specific sequences of interest.

\subsubsection{MethyLight}

MethyLight is a fluorescence-based, quantitative real-time PCR (qRT-PCR) method developed by Eads et al. [Eads et al., 2000]. Bisulfite-converted DNA is used as the template for qRT-PCR reactions using TaqMan (LifeTech, Inc.) primer-probes designed against the methylated and unmethylated versions of the target sequence. The high sensitivity of this method enables the detection of a very low abundance of hypermethylated alleles.

\subsubsection{Microarray-based methods}

DNA microarrays use several methods for detecting the methylation status of sequences represented on the array, with specificity provided by either hybridization or enzymatic specificity. Whole-genome coverage in this method is possible, but limited to the probes on the microarray. An example of a hybridization-based method is the Methylation-Specific Oligonucleotide Microarray (MSO) developed by Gitan et al. [Gitan et al., 2002]. In this method, bisulfite-modified DNA is amplified by PCR and hybridized to the array. For each interrogated sequence, the array contains separate probes specific for the unmethylated and methylated version of the sequence. The relative intensity of the signals for the two probes indicates the methylation status of the sequence. Since hybridization does not reliably distinguish between sequences that differ by a single base-pair, this method does not offer single base-pair resolution.

A microarray platform that depends on the specificity of DNA polymerase to detect methylation status is the Illumina HumanMethylation27 BeadChip (Illumina, Inc.). In this method, for each $\mathrm{CpG}$ site interrogated, separate probes for the methylated version and the unmethylated version of the $\mathrm{CpG}$ site are present on the microarray. Bisulfiteconverted genomic DNA is hybridized to the microarray, and primer extension with fluorescently- 
labeled nucleotides is performed. Since the 3 ' ends of the probes are positioned at the interrogated $\mathrm{CpG}$ sites, primer extension and labeling of methylated template sequences only occur when the templates are annealed to methylated probes (and vice versa for unmethylated sequences). This method provides single base-pair resolution, but as in all microarray-based methods, the content is limited to the probes present on the array.

\subsubsection{Bisulfite sequencing}

Bisulfite sequencing is the application of any sequencing method to bisulfite-converted DNA. Bisulfite sequencing has long been used to obtain single base-pair resolution DNA methylation data for targeted areas of the genome using conventional sequencing methods, but it was not until the development of next-generation sequencing technology that bisulfite sequencing of large regions of the genome could feasibly be performed. Even with nextgeneration sequencing methods, strategies such as Reduced Representation Bisulfite Sequencing (RRBS) were initially used [Meissner et al., 2005]. In RRBS, genomic DNA is digested with a restriction enzyme (e.g. Bgl II) and size selected. This separates the genome into discrete bins based on the size of the fragments. DNA from selected bins (e.g. 500-600 bp) is bisulfite-converted and sequenced. This strategy decreases the number of total sequencing reads required to obtain sufficient sequencing depth to obtain quantitative assessments of methylation status for the covered sequences. In addition, since mapping of bisulfite-converted sequences to a reference genome is difficult, RRBS decreases the effective size of the reference genome because of the decreased complexity of the sequences. In our example, only sequences from the reference genome present in 500-600 bp Bgl II fragments would need to be considered.

Another method for performing large-scale targeted bisulfite sequencing has recently been described in two publications [Ball et al., 2009; Deng et al., 2009]. This strategy applies the use of padlock probes to amplify 10,000-30,000 selected short regions of the genome for sequencing. Although this approach is sequencing-based, a specific padlock probe must be designed for each short target region. Therefore, it has many of the drawbacks of microarray methods, including low overall coverage and difficulty in covering certain sequences due to probe design considerations.

Whole-genome bisulfite sequencing has recently become feasible because of improvements in next-generation sequencing technology and bioinformatic methods. A complete singlebase pair resolution map of methylation of a plant genome has been reported [Lister et al., 2008], and projects to complete "methylome" maps of mammalian cells are underway.

\section{DNA methylation in ES cells}

In this section, we will review the evidence for the functionality of DNA methylation in ESCs, the existing DNA methylation data from ESCs, and the emerging data on how DNA methylation in ESCs impacts gene expression and the other epigenetic factors.

\subsection{Functionality of DNA methylation in ES cells}

There are two types of DNA methyltransferases. Dnmt1 is a "maintenance" DNA methyltransferase, and is responsible for methylating cytosines at hemimethylated $\mathrm{CpG}$ sites. Dnmt3a and Dnmt3b are "de novo" DNA methyltransferases, and methylate completely unmethylated loci. During early embryonic development, DNA methylation marks other than those at imprinted sites are first erased; then Dnmt3a and Dnmt3b are expressed at high levels and are thought to establish the normal embryonic methylation pattern [Kaneda et al., 2004; Ueda et al., 2006]. 
It has been shown that embryonic lethality results if the normal DNA methylation patterns are disrupted by absence of Dnmt1 [Li et al, 1993]. Experiments in conditional mutants have shown that offspring of female animals that lack Dnmt3a specifically in germ cells, die in utero and have disrupted DNA methylation and allele-specific expression at multiple maternally imprinted loci [Kaneda et al., 2004]. Dnmt3a conditional mutant males were shown to have impaired spermatogenesis. When spermatogonia were examined, they were demethylated at two of the three paternally imprinted loci examined. Interestingly, both female and male Dnmt $3 b$ conditional mutants and their offspring appeared to have no phenotype. In contrast, another study found embryonic lethality in Dnmt3b(-/-) mice between embryonic day14.5 and 16.5 [Ueda et al., 2006].

Li et al [Li et al., 2007] showed that Dnmt3a and Dnmt3b proteins were physically associated in mouse ESCs (mESCs), and appeared to act synergistically to methylate the Oct4 and Nanog promoters during ESC differentiation. It appears that DNA methylation is critical for differentiation but not essential for maintenance of the undifferentiated state, as it has been observed that triple knockout (Dnmt1(-/-)/Dnmt3a(-/-)/Dnmt3b(-/-)) mESCs proliferated normally and continued to express known pluripotence-associated markers, such as Oct4 and Nanog [Tsumura et al., 2006].

These cells only showed evidence of impaired proliferation when they were induced to differentiate. These results indicate that both de novo and maintenance DNA methylation are critical for early development, but are required for differentiation rather than for maintenance of the undifferentiated state. Moreover, the two de novo DNA methyltransferases appear to have synergistic and partially redundant roles.

\subsection{DNA methylation profiling of ES cells}

Human embryonic stem cells (hESCs) were shown to possess a unique DNA methylation signature when compared to differentiated cells and cancer cells [Ball et al., 2009; Bibikova et al., 2006; Deng et al., 2009; Fouse et al., 2008; Meissner et al., 2008], which supports the concept that a specific DNA methylation pattern may contribute to the pluripotent state. In particular, the pluripotency-associated genes Oct 4 and Nanog are largely unmethylated in ESCs and induced pluripotent stem cells (iPSCs), and methylated in differentiated cells [Mitsui et al., 2003; Okita et al., 2007].

Using a microarray approach, Bibikova et al. [Bibikova et al., 2006] compared the DNA methylation status of $1536 \mathrm{CpG}$ sites in hESCs, differentiated cells, and cancer cell lines, and identified differential methylation of 23 genes; this methylation profile could be used to accurately distinguish hESCs from differentiated cells. Meissner et al. [Meissner et al., 2008] used RRBS to assess the methylation status of the majority of CpG islands, in mESCs, $\mathrm{mESC}$-derived neural progenitor cells, and eight tissue samples. They found better association of DNA methylation status with histone modifications than with DNA sequence, and observed hypermethylation of a set of developmentally-regulated genes over long-term culture, which they suggested was similar to patterns of hypermethylation seen in tumors.

Fouse et al. [Fouse et al., 2008], used MeDIP-chip to map the methylation status of 11,201 proximal promoters in $\mathrm{mESCs}$ and found that the majority of unmethylated genes corresponded to general cellular functions, while the set of methylated genes was enriched for differentiation-associated genes. In addition, they found that promoters with low $\mathrm{CpG}$ content were more likely to be methylated than those with high $\mathrm{CpG}$ content. When the DNA methylation data were examined in conjunction with data on histone modifications $\mathrm{H} 3 \mathrm{~K} 4 \mathrm{me} 3$ (which is generally considered to be an activating mark) and H3K27me3 (a repressive mark), it was found that genes associated with H3K4me3 alone had the lowest levels of promoter methylation (40\%), 47\% of the genes with the H3K4/H3K27 "bivalent" 
mark were methylated, $70 \%$ of the genes with $\mathrm{H} 3 \mathrm{~K} 27$ alone were methylated, and $87 \%$ of the genes carrying neither histone mark were methylated. Moreover, gene expression data showed that $80 \%$ of the genes carrying neither histone mark were not expressed. These results suggested that for promoters occupied by histones methylated at $\mathrm{H} 3 \mathrm{~K} 4$ and/or H3K27, occupancy of promoter sequences by an activating histone mark (i.e. H3K4) is anticorrelated with DNA methylation, while occupancy by a repressive histone mark (i.e. H3K27) is correlated with DNA methylation. Promoters that lacked both histone marks were highly methylated, and DNA methylation status was a good predictor of gene expression.

Irizarry et al. [Irizarry et al., 2009] studied the methylation status of colon cancer cells and tissue samples using a comprehensive high-throughput array-based relative methylation (CHARM) [Irizarry et al., 2008]. Although this study did not analyze pluripotent stem cells, the results highlight the fact that differential methylation of regions distant from promoterassociated $\mathrm{CpG}$ islands is an important factor to consider. The authors identified over 16,000 regions of tissue-specific differentially methylation regions (T-DMRs). Most T-DMRs and regions that were differentially methylated between normal and tumor tissue were not found in promoter-associated $\mathrm{CpG}$ islands, but rather in regions up to $2 \mathrm{~kb}$ away, in areas they called " $\mathrm{CpG}$ island shores." They also found that the methylation state of these $\mathrm{CpG}$ island shores correlated strongly with gene expression.

Deng et al, used padlock probes and next-generation sequencing to compare DNA methylation at 66,000 CpG sites, mostly on chromosomes 12 and 20, in hESCs, iPSCs, and fibroblasts [Deng et al., 2009]. On a global level, they found that the overall DNA methylation patterns of all three cell types were quite similar, but noted that the pluripotent cells had slightly higher overall methylation levels than the fibroblast cells. They also identified 288 regions that were differentially methylated between fibroblasts and pluripotent cells.

Ball et al. [Ball et al., 2009] observed a pattern of low promoter methylation and high gene body methylation in highly expressed genes throughout the human genome in iPSCs, fibroblasts, and B-lymphocytes. The authors confirmed this observation using two independent techniques: the padlock probe approach and MSCC.

\section{Conclusion}

Pluripotent stem cells (ESCs and iPSCs) are of great interest for basic research and clinical applications because they are uniquely capable of self-renewal and differentiation into a large number of cell types. These cells make it possible for the first time to analyze the epigenetic control of pluripotence and differentiation. Understanding the epigenetic regulation of stem cells will help shed light on the molecular basis of normal development, and help in understanding the abnormal processes that underlie human developmental disorders and cancers. In this review, we have focused on the current methods used for DNA methylation analysis, and the key studies focused on studying DNA methylation in pluripotent stem cells. In the last several years, rapid improvements in high-throughput molecular analysis methods have resulted large datasets from analysis of the pluripotent stem cell molecular phenotype, including not only DNA methylation, but also gene expression, microRNA, and chromatin modification. This torrent of information will increase as sequencing-based methods become more reliable and affordable, and the next challenge will be to integrate and interpret the data, to unlock the biological significance of the observed epigenetic changes that occur when pluripotent stem cells undergo differentiation. 


\section{Acknowledgments}

Contract Grant Sponsor LCL is supported by NIH 5K12HD001259-10. GA and JFL are supported by CIRM TR1-01250.

\section{References}

Ball MP, Li JB, Gao Y, Lee JH, LeProust EM, Park IH, Xie B, Daley GQ, Church GM. Targeted and genome-scale strategies reveal gene-body methylation signatures in human cells. Nat Biotechnol. 2009; 27:361-8. [PubMed: 19329998]

Bartel DP. MicroRNAs: target recognition and regulatory functions. Cell. 2009; 136:215-33. [PubMed: 19167326]

Bibikova M, Chudin E, Wu B, Zhou L, Garcia EW, Liu Y, Shin S, Plaia TW, Auerbach JM, Arking DE, Gonzalez R, Crook J, Davidson B, Schulz TC, Robins A, Khanna A, Sartipy P, Hyllner J, Vanguri P, Savant-Bhonsale S, Smith AK, Chakravarti A, Maitra A, Rao M, Barker DL, Loring JF, Fan JB. Human embryonic stem cells have a unique epigenetic signature. Genome Res. 2006; 16:1075-83. [PubMed: 16899657]

Bibikova M, Laurent LC, Ren B, Loring JF, Fan JB. Unraveling epigenetic regulation in embryonic stem cells. Cell Stem Cell. 2008; 2:123-34. [PubMed: 18371433]

Bird A. DNA methylation patterns and epigenetic memory. Genes Dev. 2002; 16:6-21. [PubMed: 11782440]

Bird AP. CpG-rich islands and the function of DNA methylation. Nature. 1986; 321:209-13. [PubMed: 2423876]

Bird AP, Southern EM. Use of Restriction Enzymes to Study Eukaryotic DNA Methylation .1. Methylation Pattern in Ribosomal DNA from Xenopus-Laevis. Journal of Molecular Biology. 1978; 118:27-47. [PubMed: 625056]

Costello JF, Fruhwald MC, Smiraglia DJ, Rush LJ, Robertson GP, Gao X, Wright FA, Feramisco JD, Peltomaki P, Lang JC, Schuller DE, Yu L, Bloomfield CD, Caligiuri MA, Yates A, Nishikawa R, Su Huang H, Petrelli NJ, Zhang X, O'Dorisio MS, Held WA, Cavenee WK, Plass C. Aberrant CpGisland methylation has non-random and tumour-type-specific patterns. Nat Genet. 2000; 24:132-8. [PubMed: 10655057]

Cross SH, Charlton JA, Nan X, Bird AP. Purification of CpG islands using a methylated DNA binding column. Nat Genet. 1994; 6:236-44. [PubMed: 8012384]

Davuluri RV, Grosse I, Zhang MQ. Computational identification of promoters and first exons in the human genome. Nat Genet. 2001; 29:412-7. [PubMed: 11726928]

Deng J, Shoemaker R, Xie B, Gore A, LeProust EM, Antosiewicz-Bourget J, Egli D, Maherali N, Park IH, Yu J, Daley GQ, Eggan K, Hochedlinger K, Thomson J, Wang W, Gao Y, Zhang K. Targeted bisulfate sequencing reveals changes in DNA methylation associated with nuclear reprogramming. Nat Biotechnol. 2009; 27:353-60. [PubMed: 19330000]

Down TA, Rakyan VK, Turner DJ, Flicek P, Li H, Kulesha E, Graf S, Johnson N, Herrero J, Tomazou EM, Thorne NP, Backdahl L, Herberth M, Howe KL, Jackson DK, Miretti MM, Marioni JC, Birney E, Hubbard TJ, Durbin R, Tavare S, Beck S. A Bayesian deconvolution strategy for immunoprecipitation-based DNA methylome analysis. Nat Biotechnol. 2008; 26:779-85. [PubMed: 18612301]

Eads CA, Danenberg KD, Kawakami K, Saltz LB, Blake C, Shibata D, Danenberg PV, Laird PW. MethyLight: a high-throughput assay to measure DNA methylation. Nucleic Acids Res. 2000; 28:E32. [PubMed: 10734209]

Fouse SD, Shen Y, Pellegrini M, Cole S, Meissner A, Van Neste L, Jaenisch R, Fan G. Promoter CpG methylation contributes to ES cell gene regulation in parallel with Oct4/Nanog, PcG complex, and histone H3 K4/K27 trimethylation. Cell Stem Cell. 2008; 2:160-9. [PubMed: 18371437]

Fraga MF, Ballestar E, Paz MF, Ropero S, Setien F, Ballestar ML, Heine-Suner D, Cigudosa JC, Urioste M, Benitez J, Boix-Chornet M, Sanchez-Aguilera A, Ling C, Carlsson E, Poulsen P, Vaag A, Stephan Z, Spector TD, Wu YZ, Plass C, Esteller M. Epigenetic differences arise during the lifetime of monozygotic twins. Proc Natl Acad Sci U S A. 2005; 102:10604-9. [PubMed: 16009939] 
Frommer M, McDonald LE, Millar DS, Collis CM, Watt F, Grigg GW, Molloy PL, Paul CL. A genomic sequencing protocol that yields a positive display of 5-methylcytosine residues in individual DNA strands. Proc Natl Acad Sci U S A. 1992; 89:1827-31. [PubMed: 1542678]

Gardiner-Garden M, Frommer M. CpG islands in vertebrate genomes. J Mol Biol. 1987; 196:261-82. [PubMed: 3656447]

Gitan RS, Shi H, Chen CM, Yan PS, Huang TH. Methylation-specific oligonucleotide microarray: a new potential for high-throughput methylation analysis. Genome Res. 2002; 12:158-64. [PubMed: 11779841]

Hatada I, Hayashizaki Y, Hirotsune S, Komatsubara H, Mukai T. A Genomic Scanning Method for Higher Organisms Using Restriction Sites as Landmarks. Proceedings of the National Academy of Sciences of the United States of America. 1991; 88:9523-9527. [PubMed: 1946366]

Herman JG, Graff JR, Myohanen S, Nelkin BD, Baylin SB. Methylation-specific PCR: a novel PCR assay for methylation status of CpG islands. Proc Natl Acad Sci U S A. 1996; 93:9821-6. [PubMed: 8790415]

Herman JG, Latif F, Weng Y, Lerman MI, Zbar B, Liu S, Samid D, Duan DS, Gnarra JR, Linehan WM, et al. Silencing of the VHL tumor-suppressor gene by DNA methylation in renal carcinoma. Proc Natl Acad Sci U S A. 1994; 91:9700-4. [PubMed: 7937876]

Irizarry RA, Ladd-Acosta C, Carvalho B, Wu H, Brandenburg SA, Jeddeloh JA, Wen B, Feinberg AP. Comprehensive high-throughput arrays for relative methylation (CHARM). Genome Res. 2008; 18:780-90. [PubMed: 18316654]

Irizarry RA, Ladd-Acosta C, Wen B, Wu Z, Montano C, Onyango P, Cui H, Gabo K, Rongione M, Webster M, Ji H, Potash JB, Sabunciyan S, Feinberg AP. The human colon cancer methylome shows similar hypo- and hypermethylation at conserved tissue-specific $\mathrm{CpG}$ island shores. Nat Genet. 2009; 41:178-86. [PubMed: 19151715]

Jones PA, Laird PW. Cancer epigenetics comes of age. Nat Genet. 1999; 21:163-7. [PubMed: 9988266]

Kaneda M, Okano M, Hata K, Sado T, Tsujimoto N, Li E, Sasaki H. Essential role for de novo DNA methyltransferase Dnmt3a in paternal and maternal imprinting. Nature. 2004; 429:900-3. [PubMed: 15215868]

Li E, Beard C, Jaenisch R. Role for DNA methylation in genomic imprinting. Nature. 1993; 366:3625. [PubMed: 8247133]

Li JY, Pu MT, Hirasawa R, Li BZ, Huang YN, Zeng R, Jing NH, Chen T, Li E, Sasaki H, Xu GL. Synergistic function of DNA methyltransferases Dnmt3a and Dnmt3b in the methylation of Oct4 and Nanog. Mol Cell Biol. 2007; 27:8748-59. [PubMed: 17938196]

Lister R, O'Malley RC, Tonti-Filippini J, Gregory BD, Berry CC, Millar AH, Ecker JR. Highly integrated single-base resolution maps of the epigenome in Arabidopsis. Cell. 2008; 133:523-36. [PubMed: 18423832]

Meissner A, Gnirke A, Bell GW, Ramsahoye B, Lander ES, Jaenisch R. Reduced representation bisulfite sequencing for comparative high-resolution DNA methylation analysis. Nucleic Acids Res. 2005; 33:5868-77. [PubMed: 16224102]

Meissner A, Mikkelsen TS, Gu H, Wernig M, Hanna J, Sivachenko A, Zhang X, Bernstein BE, Nusbaum C, Jaffe DB, Gnirke A, Jaenisch R, Lander ES. Genome-scale DNA methylation maps of pluripotent and differentiated cells. Nature. 2008; 454:766-70. [PubMed: 18600261]

Mitsui K, Tokuzawa Y, Itoh H, Segawa K, Murakami M, Takahashi K, Maruyama M, Maeda M, Yamanaka S. The homeoprotein Nanog is required for maintenance of pluripotency in mouse epiblast and ES cells. Cell. 2003; 113:631-42. [PubMed: 12787504]

Okita K, Ichisaka T, Yamanaka S. Generation of germline-competent induced pluripotent stem cells. Nature. 2007; 448:313-7. [PubMed: 17554338]

Robertson KD. DNA methylation and human disease. Nat Rev Genet. 2005; 6:597-610. [PubMed: 16136652]

Saxonov S, Berg P, Brutlag DL. A genome-wide analysis of CpG dinucleotides in the human genome distinguishes two distinct classes of promoters. Proc Natl Acad Sci U S A. 2006; 103:1412-7. [PubMed: 16432200] 
Schones DE, Zhao K. Genome-wide approaches to studying chromatin modifications. Nat Rev Genet. 2008; 9:179-91. [PubMed: 18250624]

Strahl BD, Allis CD. The language of covalent histone modifications. Nature. 2000; 403:41-5. [PubMed: 10638745]

Tsumura A, Hayakawa T, Kumaki Y, Takebayashi S, Sakaue M, Matsuoka C, Shimotohno K, Ishikawa F, Li E, Ueda HR, Nakayama J, Okano M. Maintenance of self-renewal ability of mouse embryonic stem cells in the absence of DNA methyltransferases Dnmt1, Dnmt3a and Dnmt3b. Genes Cells. 2006; 11:805-14. [PubMed: 16824199]

Ueda Y, Okano M, Williams C, Chen T, Georgopoulos K, Li E. Roles for Dnmt3b in mammalian development: a mouse model for the ICF syndrome. Development. 2006; 133:1183-92. [PubMed: 16501171]

Waddington CH. The epigenotype. Endeavour. 1942; 1:18-20.

Weber M, Davies JJ, Wittig D, Oakeley EJ, Haase M, Lam WL, Schubeler D. Chromosome-wide and promoter-specific analyses identify sites of differential DNA methylation in normal and transformed human cells. Nat Genet. 2005; 37:853-62. [PubMed: 16007088]

Wu C, Morris JR. Genes, genetics, and epigenetics: a correspondence. Science. 2001; 293:1103-5. [PubMed: 11498582]

Zhang X, Yazaki J, Sundaresan A, Cokus S, Chan SW, Chen H, Henderson IR, Shinn P, Pellegrini M, Jacobsen SE, Ecker JR. Genome-wide high-resolution mapping and functional analysis of DNA methylation in arabidopsis. Cell. 2006; 126:1189-201. [PubMed: 16949657] 